\title{
Correction to: Incorporating Breastfeeding-Related Variability with Physiologically Based Pharmacokinetic Modeling to Predict Infant Exposure to Maternal Medication Through Breast Milk: a Workflow Applied to Lamotrigine
}

Cindy H. T. Yeung, ${ }^{1}$ Shinya Ito, ${ }^{2}$ Julie Autmizguine, ${ }^{3,4}$ and Andrea N. Edginton ${ }^{1,5}$

A Correction to this paper has been published: https://doi.org/10.1208/s12248-021-00615-8

Correction to: The AAPS Journal volume 23, Article number: 70 (2021)

https://doi.org/10.1208/s12248-021-00599-5

This correction is to update Table I, and to delete a paragraph from the "Results" section.

The original article has been corrected.

Publisher's Note Springer Nature remains neutral with regard to jurisdictional claims in published maps and institutional affiliations.

The online version of the original article can be found at https:// doi.org/10.1208/s12248-021-00599-5

\footnotetext{
${ }^{1}$ School of Pharmacy, University of Waterloo, Waterloo, Ontario, Canada.

${ }^{2}$ Division of Clinical Pharmacology and Toxicology, Hospital for Sick Children, University of Toronto, Toronto, Ontario, Canada.

${ }^{3}$ Department of Pediatrics \& Department of Pharmacology and Physiology, Université de Montréal, Montréal, Québec, Canada.

${ }^{4}$ Research Center, Centre Hospitalier Universitaire Sainte-Justine, Université de Montréal, Montréal, Québec, Canada.

${ }^{5}$ To whom correspondence should be addressed. (e-mail: aedginto@uwaterloo.ca)
} 